\title{
Andrew Paul Leonard: Capturing the Cover of Time Magazine
}

\author{
By Lise Millay Stevens, MA \\ lise_m_stevens@hotmail.com
}

If beauty is in the eye of the beholder, then microscopic photographer Andrew Paul Leonard might have a lot to explain. After all, touting the aesthetic merits of an eosinophil (picture that let alone pronounce it) hardly brings to mind the rugged splendor of Ansel Adam's "El Capitan" or the quirky languidness of Richard Avedon's "Dovima with Elephants." Yet, one look at these starkly detailed images reveals a textured, beautiful world reminiscent of the fancy of Yellow Submarine and the graphic logic of M.C.Escher.

Andrew's journey into this invisible world started when he was studying both photography and biology at Hampshire College in Amherst, Mass. "I became very interested in photomicrography as a result of studying different types of leukocytes (white blood cells) - I became fascinated by the morphology, colors, and shapes. My favorite type actually turned out to be an eosinophil." The cells appealed to his artistic as well as his scientific sensibilities. "They were quite beautiful and colorful after applying Wright's stain, with varying shades of red and purple. My fascination with 'inner space' had been ignited. This was a whole new frontier for me to explore with my new camera: the microscope."

In 1983, a scanning electron microscope (SEM) was donated to Hampshire. Andrew, who had recently become acquainted with the photography of [scientist-photographer] David Scharf, eagerly threw himself into learning to use it, but unfortunately it was not in the best shape. "It even caught fire several times!" he notes. "If I wanted to pursue electron microscopy, I would have to look elsewhere."

After searching for a new venue to practice his newly-found love, Andrew discovered that several electron microscopes were being used at the University of Massachusetts and that an SEM was available in the Microbiology Department. He seized the opportunity and arranged to use it for an upcoming project, and in 1984 began searching for an internship in biology at a lab with an electron microscope.

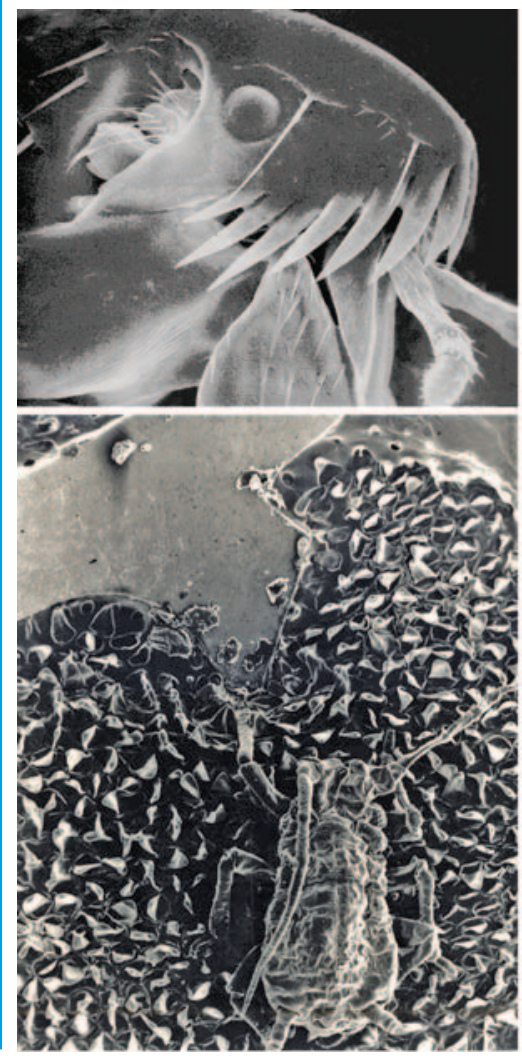

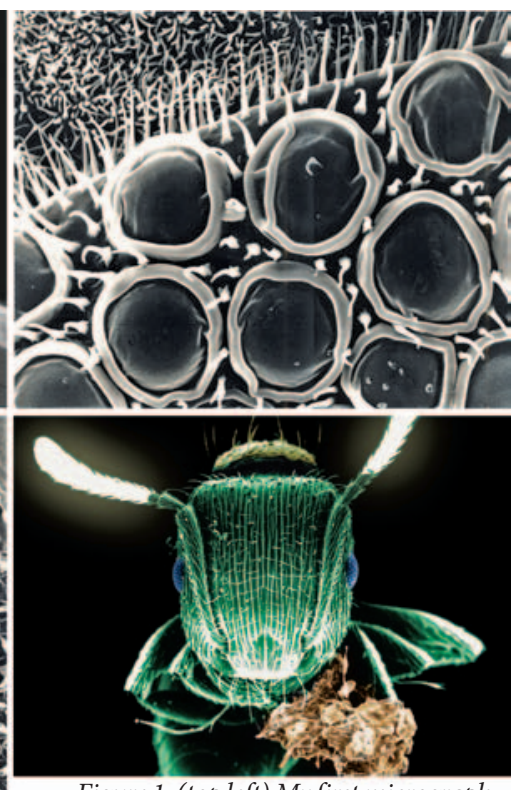

Figure 1. (top left) My first micrograph "The flea that bit me."

Figure 2A. Compound eye of unidentified insect.

Figure 2B Aphid on marigold pedal with watch gear.

Figure 2C Ant eating crumb of brownie (recent digital enhancement).
That year, he landed a summer internship at Cornell Medical College in New York City and soon mastered the JOEL $100 \mathrm{CX} \mathrm{SEM} /$ TEM (transmission electron microscope) while working in the department of cell biology and anatomy. "This was my first opportunity to finally see and work with a scanning / transmission electron microscope," An-

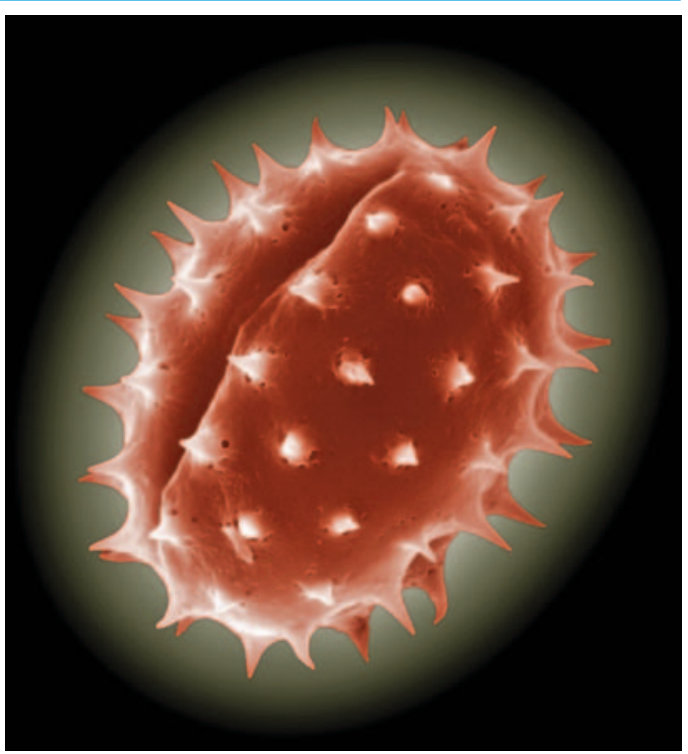

Figure 3 Glowing Pollen, special effects created optically with Forox camera. explains. "The very first photograph I shot was of a flea which had bitten me in the leg while I was playing piano. After capturing the flea in a plastic bag, I transported it to the electron microscope and recorded my first electron micrograph." (Figure 1).

Upon returning to Hampshire College in the fall of 1984, Andrew decided that his final project would be to mount a public exhibit of electron micrographs at the college's main gallery. "Aside from simple photographs of small things, my vision for the showing was to combine subjects which one normally would not expect to see side by side," Andrew says. "I really wanted to inject some comical elements in my subject matter." One photograph along these lines was of an aphid perched atop a gear taken from a watch. The exhibition, in May of 1985, was a success (Figures $2 \mathrm{a}-2 \mathrm{c}$ ).

After graduation, Andrew accepted a position at the University of Massachusetts as an EM technician in the microbiology department, resulting in his straying away from microscopy in general. "My workdays were filled with preparing samples, maintaining the dark room, and working with the SEM on mundane projects," Andrew notes. "After many months of having to focus on research, which did not particularly interest me, I decided to make a change and look for different work in New York City."

He moved to New York City in 1987, and was fortunate to secure employment with a small audiovisual company specializing in multi-projector slide presentations. He became a special-effects cameraman and learned optical special effects, including applying color gels to light sources, using frosted glass and masks to create drop shadows, and creating zoom effects.

"Audiovisual companies enjoyed a great deal of success in the late 1980s," Andrew reminisces. "The animation camera I used was called a Forox and I was determined to be proficient in its use despite the 10- to 13-hour workdays. I decided one day to incorporate some Forox camera special effects on one of my micrographs of pollen. I made a large film negative and positive of the image, illuminated and colored the bottom light source of the Forox camera, placed the film negative below a piece of translucent glass, placed the film positive on top and created a 'glowing pollen' " (Figure 3).

The concepts, such as Adobe Photoshop, that Andrew had learned as a cameraman would become invaluable in the emerging digital image revolution, . Clearly, computers, scanners, and graphic software applications were the wave of the future, sweeping away analogue photography and darkroom work in their wake. 


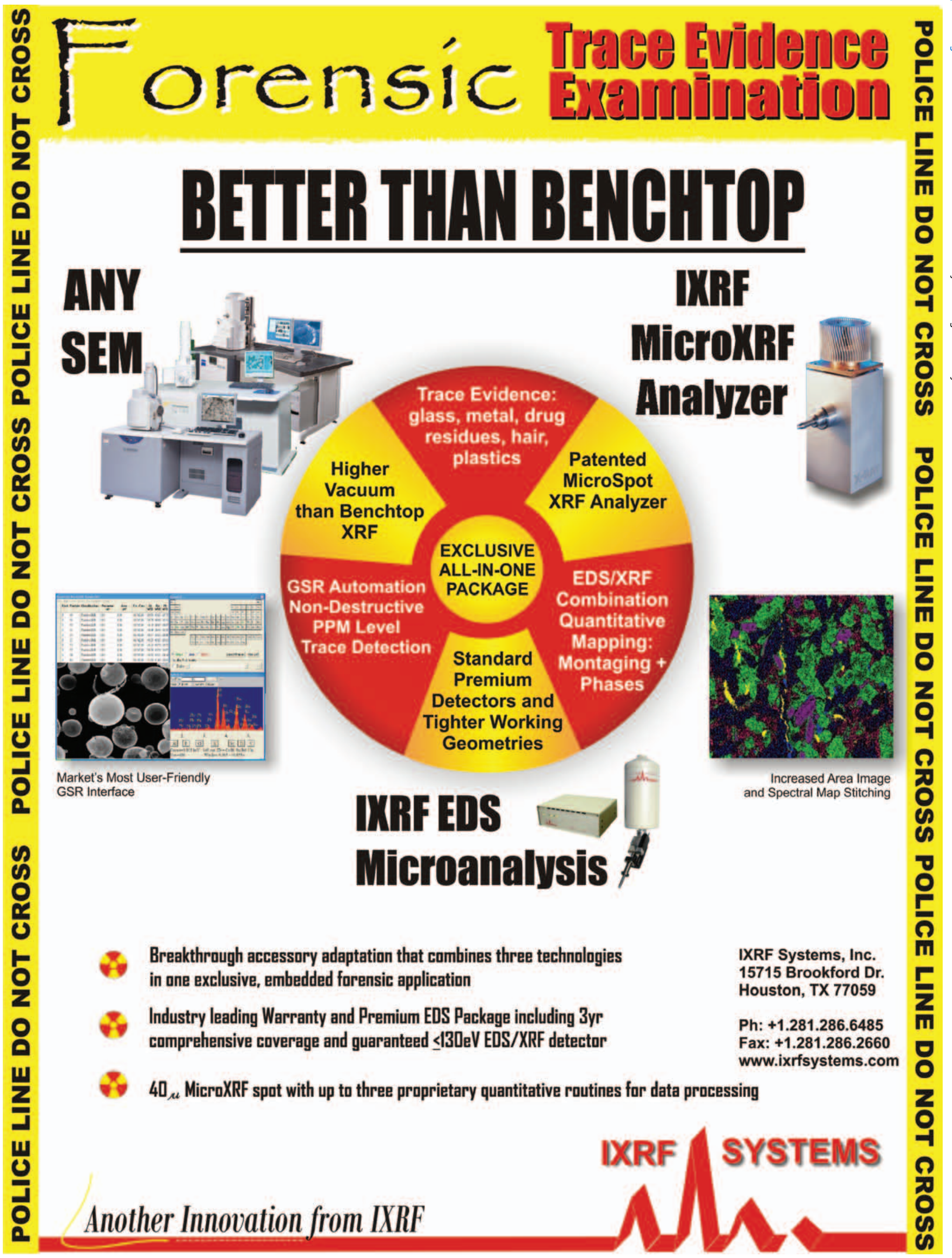




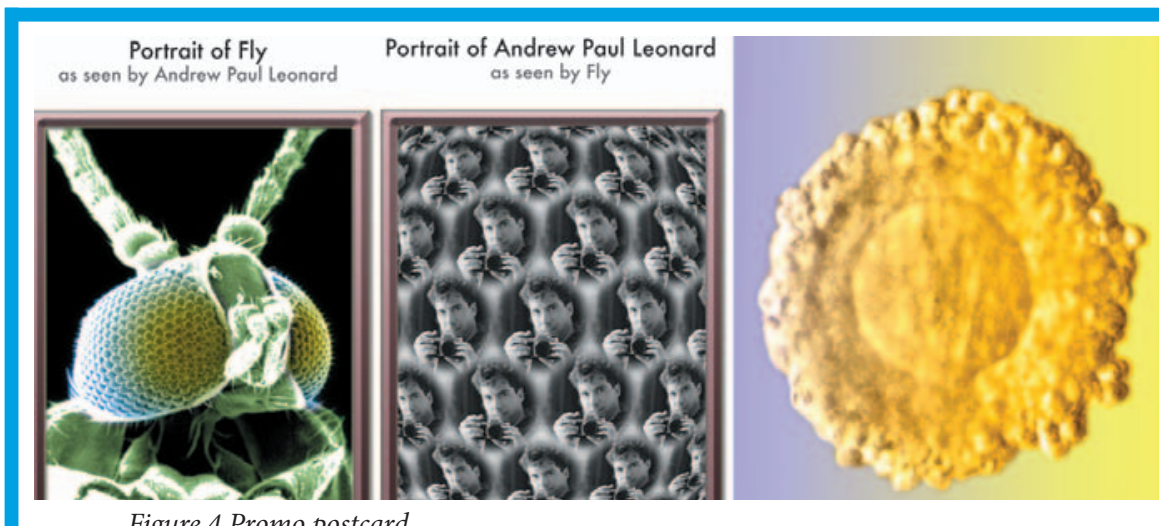

professionals-these jobs are few and far between and you want to be the first person who comes to mind when there is a need." He adds that the ongoing challenge of procuring samples is an added layer of difficulty which involves a lot of time working the phones against a tight deadline, often less than a week.

"That's just the nature of the advertising industry," Andrew muses. "I do not own my own microscope so I must continually find one available to rent. At times I've had less than a week to find a sample, prepare it, and make arrangements with a facility that has an available microscope and will allow me to use it."

His dedication has paid off, however. Last July,

Figure 4 Promo postcard.

Figure 5 Human Ovum, Nomarski optical microscopy with digital color enhancement. Andrew was contacted by Time magazine about his progress with growing human embryonic stem cells. He

When the recession of the late 1980s hit, Andrew took stock of his situation and the changing environment. "The job market had become saturated with graphic artists and the days of audiovisual Forox work were long gone," he remembers. "I had always secretly wanted to work for myself and since I had experience in video production and sales, I decide to launch APL (his initials) Microscopic."

He set his sights on commercial microscopic photography for pharmaceutical advertising, and dedicated himself to the selling and marketing of his new business. "Cold calls are necessary and you have to be tenacious and persevere," Andrew says. "Rejection was an everyday occurrence, which I had to get past quite quickly. I had to learn who my potential customers were and dazzle them. I also had to learn how to get past the office gate keepers.

Andrew designed a series of postcards and color sample sheets to entice new clients. "One postcard I designed incorporated using conventional and microscopy artwork-I used Adobe Photoshop to achieve a dazzling effect which I was confident would bring attention to what I do creatively and inspire ideas for my potential clients," (Figure 4).

One of his first major assignments was optical microscopy of a human ovum (Figure 5) for a pharmaceutical company that manufacturers fertility drugs. Getting the job was hard enough, but procuring the samples needed for the images was an even greater challenge, proving to be almost as difficult as the artistic microscopy work itself. On one of his most successful jobs for the drug Lipitor, Andrew was asked for an SEM image of a healthy human coronary artery by the end of the week.

"I called just about every pathology lab I could think of and learned just how difficult it was to procure a clean, healthy, human coronary artery," Andrew explains. "One expert suggested that I should use a pig artery, as most of these were by nature clean looking and healthy. The client found that unacceptable." He pressed on with his search and identified a pathology department with the needed artery which was sent out to him immediately. The image of that healthy coronary artery became part of one of the most successful drug launches in U.S. history (Figure 6).

Another notable assignment was a request to photograph follicle stimulating hormone (FSH) crystals. "I was going to use polarizing light microscopy as well as scanning," Andrew says. "After taking on that assignment, I discovered that FSH had not been crystallized so I proposed scanning electron microscopy of the FSH product as is. The result was truly amazing-there were endless shots in the sample, all different from one another (Figure 7).

As business grew, Andrew broadened his services to include not just microscopy, but digital media production for medical institutions. He designed and optimized digital posters, grant proposals, and digital video. He also launched "digital media centers" at major research facilities, including the Mount Sinai School of Medicine and around the same time started another company, APL Biomedical Communications.

So all told, what is the downside of being a commercial micrographer? "Sales and marketing," Andrew emphatically notes. "You have to spend 99 percent of your time on the phone and visiting advertising had pitched the magazine a few months earlier and informed them that he was close to having viable images for publication. "Their deadline was tight but luckily I had the image of the bone marrow stem cell ready to go," Andrew says. The image appeared on the cover of the August 7, 2006 issue. A similar image is on the cover of this issue.

So what does the future hold for this microscopy entrepreneur? Once again, his artistic sensibility is guiding his course. "Currently, I am concentrating more on microscopy as an art form," Andrew notes. $\mathrm{He}$ has been using a ZEISS SMT ULTRA 55 field emission STEM for his images. "I love it. It has given me the ability to see details and topography that no other scope afforded. I first photographed human embryonic stem cells with it in September 2006."

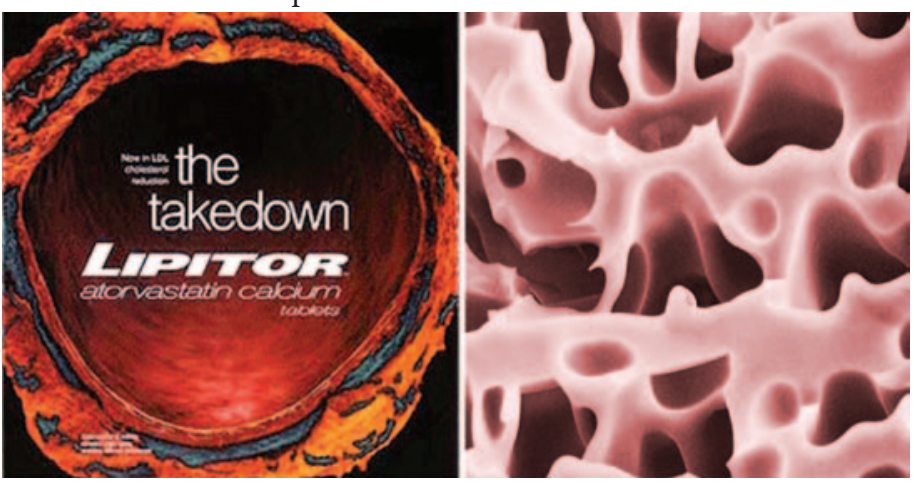

Figure 6 Launch of Pfizer's Lipitor, ${ }^{\circ}$ showing healthy coronary artery. Figure 7 Fertility drug.

Andrew hopes to show these and other high-resolution images taken with the Zeiss some time next year. "My interest in stem cells actually goes back almost 10 years when I photographed bone marrow stems. With the increasing debate on how and when it is appropriate to utilize human embryonic stem cells, I've come to realize just how important these images are," he expounds. "My collaborators at Mount Sinai School of Medicine, whom I have great respect for, have tackled the difficult task of growing and preparing human embryonic stem cells for scanning; the cells are fragile, and much more difficult to prepare for electron microscopy than other stem cells, such as mice."

Interested readers can visit Andrew Paul Leonard's APL Microscopic web sites at www.aplmicro.com or www.aplbiomed.com. Andrew Leonard would like to thank some of the many people who have helped him over the past few years. These include John H. Morrison, Patrick Hof, Micheal Linden, Els Henckaerts, Miki Rifkin, Charles Mobbs, Peter Rapp, Gordon Keller, Andrea Gore, Marion Kennedy, Dee Breger, Nina Lampen, James Dennis, Erika Musante, John Yorston, Beth Bresson, Peter Clark, Doug Wei, Lee Cohen-Gould, Frank Macaluso, Lambros Kromidas, William Janssen, Margaret Baron, David Frey, Adam Asch, Karl Jepsen, Andrea Gore, Mitch Schaffler, Juan Badimon, Sandra Mathews, Fred Wirth, Nancy Lowry, Abraham Ravett, Jerome Leibling, Ronald Gordon, Jon Weider, Ruben Abagyan, Jeffrey Fass, Dan Seifert, and Paul Willard. 


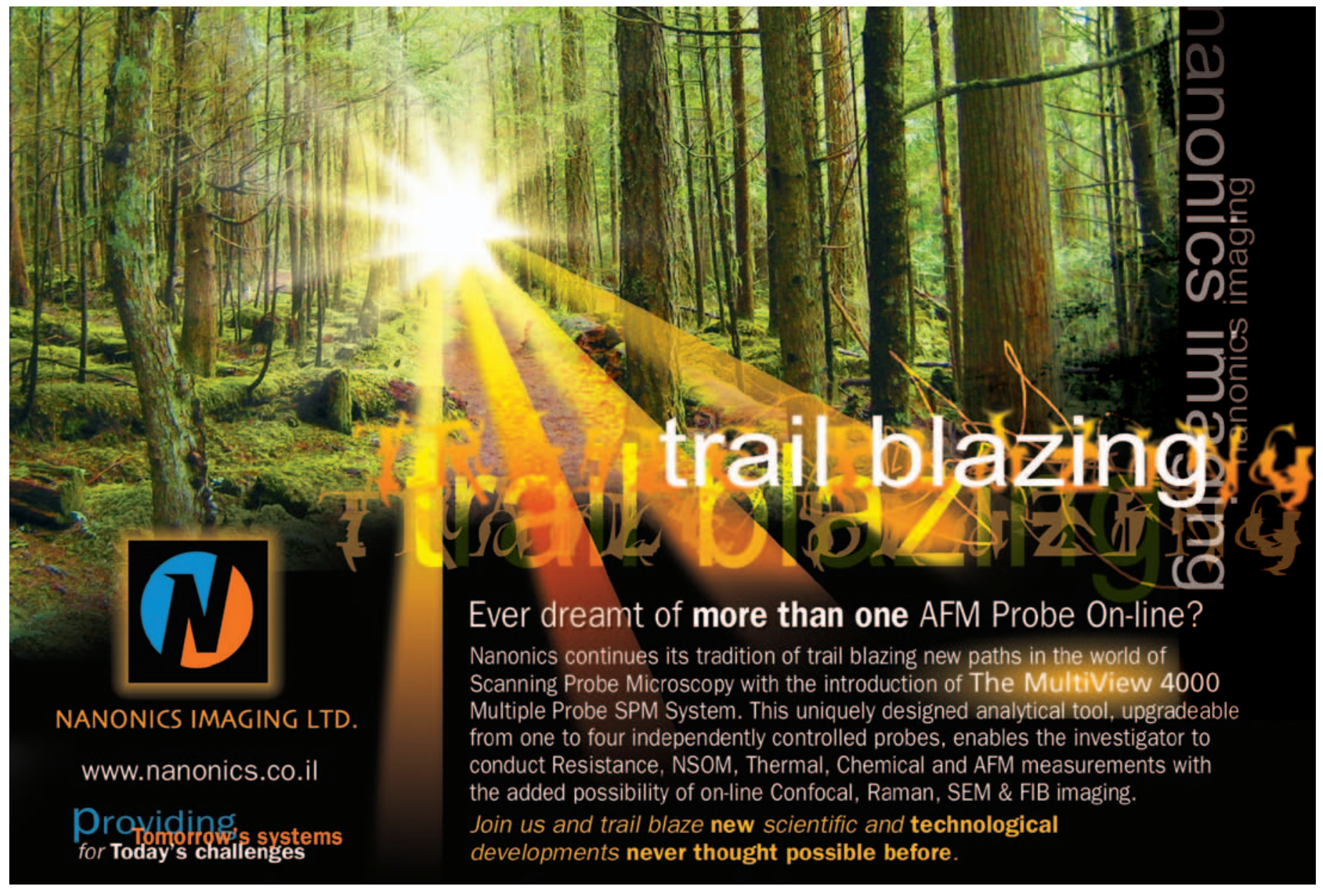

\section{MBL Biological Discovery in Woods Hole Founded in 1888 as the Marine Biological Laboratory \\ 2007 Microscopy Courses}

ANALYTICAL \& QUANTITATIVE LIGHT MICROSCOPY May 9 - May 18,2007

Application Deadline: January 24, 2007

This comprehensive course provides an in-depth examination of the theory of image formation and the application of video methods for exploring subtle interactions between light and the specimen.

\section{OPTICAL MICROSCOPY \& IMAGING \\ IN THE BIOMEDICAL SCIENCES \\ October 9 - October 18, 2007 \\ Application Deadline: June 29, 2007}

This course will enable the participant to obtain and interpret microscope images of high quality to perform quantitative optical measurements and to produce video and digital records for documentation and analysis.

For further information and applications, visit our website:

www.mbl.edu/education

or contact: Admissions Coordinator

admissions@mbl.edu, (508)289-7401

Women and minorities encouraged to apply.

The MBL is an EEO/Affirmative Action Institution.

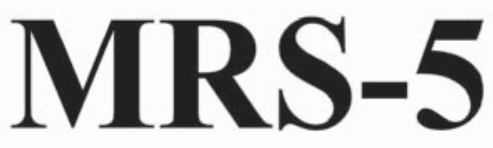

We are ISO-9000 certified and ISO-17025 accredited Microscopy Calibration Standard Now you can calibrate from $1,000 \mathrm{X}$ to $1,000,000 X !$

This is our fourth generation, traceable, magnification reference standard for all types (SEM, FESEM, Optical, STM, AFM, etc.) of microscopy. The MRS- 5 has multiple $\mathrm{X}$ and $\mathrm{Y}$ pitch patterns ranging from $80 \mathrm{~nm}( \pm 1 \mathrm{~nm})$ to $2 \mu \mathrm{m}$ and 3 bar targets from $80 \mathrm{~nm}$ to $3 \mu \mathrm{m}$. There is also a STM test pattern.

Free web resource guide!

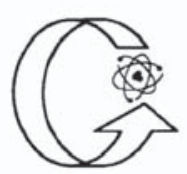

\section{GELLER} MICROÅNALYTICAL LABORATORY, Inc.

426e Boston St., Topsfield, Ma 01983 www.gellermicro.com 